\title{
Ensino e aprendizagem da escrita acadêmica na universidade: o que narram professores e estudantes?
}

\author{
Teaching and learning of academic writing at the university: what do \\ teachers and students tell?
}

Fabrício Oliveira Da Silva Pós-doutor e Doutor em Educação e Contemporaneidade Universidade Estadual de Feira de Santana - UEFS. Feira de Santana, Bahia - Brasil. fosilva@uefs.br

Andrea Santana de Oliveira Licencianda em Pedagogia Universidade Estadual de Feira de Santana - UEFS.

Feira de Santana, Bahia - Brasil andrea.santanadeoliveira@yahoo.com.br

Resumo: O objetivo do trabalho é analisar estratégias de ensino e aprendizagem da escrita científica, elencadas por professores e estudantes da Universidade Estadual de Feira de Santana - UEFS. A pesquisa tem ancoragem nos princípios de uma pesquisa qualitativa. Como dispositivo de recolha de informações, foram utilizados relatos narrativos, apreendidos através de entrevistas narrativas individuais. As discussões aqui tecidas foram realizadas com base nas contribuições de autores como Anastasiou e Alves (2009 e 2012); Castelló (2009); Jovchelovitch (2002); e Burochovitch e Santos (2011); Silva (2020). O estudo permitiu concluir que apesar dos docentes afirmarem desenvolver estratégias de ensino da escrita, estas, parecem imperceptíveis aos olhares discentes. O estudo evidenciou, ainda, o fato de que os discentes utilizam, mesmo que de forma inconsciente, estratégias de aprendizagem derivadas de algumas práticas de ensino dos professores.

Palavras-chave: Escrita. Ensino Superior. Estratégias. Aprendizagem.

Abstract: The objective of the work is to analyze teaching and learning strategies of scientific writing, listed by professors and students of the State University of Feira de Santana - UEFS.

The research is anchored in the principles of qualitative research. As a device for collecting information, narrative reports were used, apprehended through individual narrative interviews. The discussions woven here were carried out based on the contributions of authors such as Anastasiou and Alves (2009 and 2012);Castelló (2009);jovchelovitch (2002); and Burochovitch and Santos (2011); Silva (2020). The study allowed us to conclude that although the professors claim to develop strategies for teaching writing, these seem imperceptible to the students' eyes. The study also evidenced the fact that students use, even if unconsciously, learning strategies derived from some teaching practices of teachers.

Keywords: Writing. University education. Strategies. Learning

Cite como

(ABNT NBR 6023:2018)

SILVA, Fabrício Oliveira da; OLIVEIRA, Andrea Santana de. Ensino e aprendizagem da escrita acadêmica na universidade: o que narram professores e estudantes? Dialogia, São Paulo, n. 37, p. 1-13, e19451, jan./abr. 2021. Disponível em: https://doi.org/10.5585/dialogia.n37.19451.

American Psychological Association (APA)

Silva, F. O. da., \& Oliveira, A. S. de. (2021, jan./abr.). Ensino e aprendizagem da escrita acadêmica na universidade: o que narram professores e estudantes? Dialogia, São Paulo, 37, p. 1-13, e19451. https://doi.org/10.5585/dialogia.n37.19451. 


\section{Introdução}

Não se pode negar o grande prestígio social atribuído à escrita. Desde os primórdios de sua criação, ela permeia a vida humana em sociedade, estando presente em vários contextos e atividades cotidianas. Dito isso, é importante frisar que este conhecimento tão indispensável para a vida social, ainda hoje não é acessível para todas as pessoas. Os que não sabem escrever acabam sendo excluídos ou marginalizados socialmente.

No contexto do Ensino Superior, a realidade não é diferente, a escrita atravessa as mais variadas áreas do conhecimento e possui estreita relação com o sucesso ou fracasso dos estudantes. Entretanto, os alunos ingressantes, mesmo tendo níveis de escrita que lhes permitiram adentrar na universidade, costumam apresentar muita dificuldade com a aquisição da aprendizagem da escrita científica, fato este, que lhes causa muita inquietação e angústia. Por parte dos docentes, há queixas recorrentes de que o sistema educacional é deficiente, no que tange ao ensino básico, o que gera uma culpabilização da escola, como se ela fosse a responsável pelas dificuldades de escrita que os estudantes evidenciam na universidade.

Diante disso, é relevante problematizar situações do ensino de escrita acadêmica, comespecial foco nas estratégias que professores utilizam na universidade. De certo modo, percebemos que a escrita é um princípio fundante para o êxito estudantil na vida universitária, o que nos leva a pensar em como as estratégias de ensino da escrita acadêmica tem encontrado assento nas práticas de docentes universitários.Há ainda a preocupação com a autonomia estudantil frente a esse processo, motivo pelo qual se faz necessário diálogos e compreensões com os discentes, a fim de entender como estestêm desenvolvido estratégias de aprendizagem de escrita, para contornar e superar suas dificuldades. Ademais, se debruçar sobre os modos e práticas de ensino e aprendizagem da escrita na universidade nos possibilita compreender como está sendo tecida a relação professor e estudante no interior desse cenário de incertezas e inquietude dos estudantes.

Para além disso, é importante frisar que este trabalho resulta de uma pesquisa maior, intitulada: Implicações didáticas para o ensino e a aprendizagem da escrita científica na universidade, desenvolvida em âmbito do Núcleo de Estudos e Pesquisas sobre Pedagogia Universitária - NEPPU, da Universidade Estadual de Feira de Santana - UEFS, o qual tem tradições em trabalhos que centralizam o foco nas práticas educativas que professores e estudantes desenvolvem para a promoção de aprendizagens na universidade. É desse princípio, que o estudo tem como objetivo analisar as principais estratégias de ensino e aprendizagem da escrita científica, elencadas pelos professores e estudantes participantes da pesquisa. Trata-se de discentes e docentes 
da Universidade Estadual de Feira de Santana, que mantiveram ao longo do ano de 2019 relações pedagógicas em âmbitos de componentes curriculares obrigatórios.

O presente texto está organizado em quatro seções, além da introdução. Na seção a seguir, abordaremos o percurso metodológico da pesquisa, evidenciando a ancoragem teóricometodológica em que o estudo foi desenvolvido e, de igual modo, apresentando a tessitura dos dispositivos de recolha de informações. Há ainda duas seções de análises, nas quais trazemos à baila as narrativas de professores e estudantes com atenção aos processos de ensino e aprendizagem da escrita na universidade. Nesse contexto, na primeira seção analítica nos atemos a evidenciar as estratégias de ensino que professores têm desenvolvido frente ao desafio de ensinar a escrita científica na universidade. Já na segunda, o foco é nas narrativas dos estudantes, promovendo reflexões em torno das estratégias que estes criam para desenvolverem aprendizagens da escrita. $\mathrm{Na}$ última seção, mas não menos importante, apresentamos as considerações finais, revelando os principais movimentos que a pesquisa permitiu concluir e revelar, além dos resultados oriundos das narrativas, àqueles que têm relação com as aprendizagens dos pesquisadores ao se aventurarem pelo movimento da pesquisa.

\section{Percurso metodológico}

A pesquisa da qual este trabalho emergiu fundamenta-se nos princípios da pesquisa qualitativa, na qual o importante é a subjetivação, pois durante a investigação científica é preciso reconhecer a complexidade do objeto de estudo, rever criticamente as teorias sobre o tema, estabelecer conceitos e teorias relevantes, usar técnicas de coleta de dados adequadas e, por fim, analisar todo o material de forma específica e contextualizada. Sobre este tipo de pesquisa Minayo (2008) defende que

[...] a pesquisa qualitativa trabalha com o universo dos significados, motivos, aspirações, crenças, valores e atitudes, o que corresponde a um espaço mais profundo das relações, dos processos e dos fenômenos que não podem ser reduzidos à operacionalização de variáveis (MINAYO, 2008, p. 21-22).

Assim, na pesquisa qualitativa, o estudo dos sentidos sobre a experiência humana deve ser feito entendendo que as pessoas interagem, interpretam e constroem compreensões sobre o que são e o que fazem, tendo na perspectiva da (auto)biografia uma metodologia que valoriza o vivido, focalizando as reflexões que aquele que narra faz de si e do modo como atua profissionalmente. (SILVA, 2020). 
Como dispositivo de pesquisa, foram utilizados relatos narrativos de duas professoras e de dois estudantes ambos do $3^{\circ}$ semestre dos cursos de Psicologia e Letras vernáculas, daUEFS, produzidos em momentos individuais, por meio dos quais foram realizadas entrevistas narrativas, a fim de que cada entrevistado pudesse relatar as estratégias de ensino e de aprendizagem da escrita acadêmica, desenvolvidas por estes, na universidade. Tais entrevistas ocorreram entre os meses de março e abril de 2020, sendo que três destas ocorreram presencialmente e uma de forma remota, utilizando a plataforma Google Meet.

Assim, como mencionado o dispositivo de recolha de informações empregado foi a entrevista narrativa, que se configura como um instrumento que visa estimular o sujeito entrevistado a contar com maior riqueza de detalhes sobre os fatos ocorridos durante sua trajetória de vida e formação. Sobre a mesma, Jovchelovitch (2002) destaca que:

Através das narrativas as pessoas lembram o que aconteceu, colocam a experiência em uma sequência, encontram possíveis explicações para isso, e jogam com a cadeia de acontecimentos que constroem a vida individual e social (JOVCHELOVITCH 2002, p. 91).

Conforme assevera a autora, bem como defende Silva (2020), as entrevistas narrativas fazem fluir o movimento experiencial que o sujeito tem desenvolvido frente a situações de sua vida, em que a memória é um fundamento central para construir sentidos para o vivido. No cenário do presente estudo, a entrevista narrativa figurou como dispositivo que facultou fluir o movimento experiencial que professores e estudantes têm desenvolvido face o trabalho com a escrita científica na universidade. As cadeias de acontecimentos foram sendo tecidas, significadas e ressignificadas pelas lembranças de professores e estudantes, congregando modos próprios de revelar entendimentos sobre, para os professores, o ensino da escrita e, para os estudantes, as estratégias de aprendizagem que ao longo de sua itinerância na universidade vão construindo para superar, contornar e enfrentar as dificuldades em torno da escrita científica.

O princípio de análise empregado nesta pesquisa, relaciona-se com o compreensivo interpretativo, conforme preconizado por Ricouer (1996), no qual, o processo de compreensão e de interpretação é tecido a partir do movimento de fluidez dos sentidos que emergem da própria narração. Nesse movimento analítico, almejou-se perceber a relação existente entre as práticas de ensino, estratégias de aprendizagem da escrita e a tessitura das narrativas em torno delas. Tal perspectiva, favoreceu uma melhor compreensão e interpretação sobre as práticas de ensino e aprendizagem da escrita empregadas na universidade.

Desse modo, a análise realizada congregou a valorização dos sentidos que se constituiu da própria reflexão e narração que cada sujeito produziu, ao construir compreensões para si a partir 
do vivido na universidade e do narrado. Ao movimento analítico dos pesquisadores, coube desenvolverum movimento compreensivo e interpretativo atencioso e respeitoso às particularidades de cada história, entendendo que na narrativa os sentidos são construídos pelos próprios sujeitos. As informações produzidas foram tratadas valorizando o movimento de produção dos significados que ao narrar o sujeito produz. Assim sendo, a análise se fundamenta em princípios de imparcialidade que adota os pesquisadores para possibilitar o movimento interpretativo e compreensivo dos colaboradores do estudo ${ }^{1 .}$

\section{Estratégias de ensino da escrita científica na universidade}

Escrever não se constitui como uma tarefa simples. As dificuldades de escrita dos estudantes põem-se em evidência, exigindo dos docentes uma postura atenta que lhes possibilite enxergar e acolher os discentes em tais dificuldades. Diante disso, as estratégias de ensino emergem neste cenário, como ferramentas indispensáveis à prática docente. Posto isso, é pertinente entender o que são estratégias e qual a sua relevância no processo de ensino e aprendizagem da escrita na universidade. Assim, segundo Anastasiou e Alves (2012) “A palavra estratégia derivada do grego strategía e do latim strategia "significa a arte de aplicar ou explorar os meios e as condições favoráveis e disponíveis, com vista à consecução de objetivos específicos" (ANASTASIOU e ALVES, 2012, p. $75-76)$.

É imprescindível destacar que este papel de estrategista do docente se constrói a partir de uma tomada de consciência que possibilite que o mesmo se coloque à disposição para ouvir os alunos e conhecer suas necessidades e principais dificuldades. No que tange, às dificuldades de escrita dos estudantes, a partir das narrativas dos sujeitos entrevistados, foi possível compreender que estas, variam desde dificuldades referentes à sua não familiaridade com os gêneros textuais solicitados no âmbito da universidade, como afirma a estudante Aline': "Pelo menos en tive muita dificuldade logo no início com... Os textos mesmo são totalmente diferentes." (Aline, entrevista narrativa, 2020).No trecho, a estudante demonstra desconhecer tais gêneros textuais, que possivelmente não lhe foram apresentados em suas práticas de escrita anteriores.

As dificuldades dos estudantes relacionam-se ainda com questões de cunho ortográfico, como é possível notar na narrativa do estudante Petrus: "Possuo algumas dificuldades ortográficas, pois, mesmo sendo de letras todo mundo tem dificuldades." (Petrus, entrevista narrativa, 2020).Entretanto, tais dificuldades ortográficas dos discentes, nem sempre são preocupações do ensino que os

\footnotetext{
${ }^{1}$ Em consonância com a recomendação do Comitê de Ética que aprovou a referida pesquisa, utilizamos a adoção de nomes fictícios para preservar a identidade dos participantes.
} 
professores realizam, pois, pressupõe-se que os estudantes chegam da Educação Básica com esses saberes desenvolvidos. A grande problemática é que nem sempre os mesmos ingressam no Ensino Superior com conhecimentos de natureza ortográfica amplamente desenvolvidos, o que vem a interferir no processo de escrita do estudante.

Para além disso, ficou nítido nas narrativas, que os docentes nem sempre conseguem enxergar as dificuldades sinalizadas pelos estudantes, visto que, em suas falas dificuldades relacionadas aos gêneros textuais, por exemplo, quase nunca aparecem. Isso se visibiliza nos trechos das narrativas das professoras Sol e Flor, que abordando as dificuldades dos estudantes, assim refletem: Então, normalmente os alunos trazem argumentos fracos para o texto e não respeitam a norma padrão.
Há inclusive erros primários eu diria de ortografia nos textos dos alunos dos cursos de letras, Letras
Vernáculas e Letras com línguas estrangeiras. Os erros ortográficos que não se esperaria de textos de
alunos na universidade (Sol, entrevista narrativa, 2020).

A dificuldade dos estudantes, com normas da ABNT, que é né, e na psicologia a gente usa bastante. Então, assim os alunos não referenciavam ou quando referenciavam, eles achavam que referenciar era mostrar o autor e colocar a palavra ipisiliteris ali como o autor colocava (Flor, entrevista narrativa, 2020).

As narrativas revelam, sobretudo, que há uma compreensão de que estudantes que chegam à universidade não devem cometer erros de ortografia, sobretudo se são estudantes dos cursos de Letras. Saber escrever bem e corretamente é instituída como obrigatoriedade na universidade, o que coloca em xeque muitos estudantes que acessam o Ensino Superior, trazendo em sua bagagem todas as dificuldades inerentes que a vida escolar na Educação Básica lhe imputou. No caso da narrativa de Flor, que aborda a dificuldade dos estudantes em usarem as normas de ABNT, a problemática fica ainda mais visível, ao se conceber que o não domínio das normas torna-se um problema para o estudante, face à necessidade desse conhecimento na área.

Portanto, fica visível, que apesar das docentes enxergarem algumas dificuldades dos alunos, estas as desconhecem na sua integralidade. O que se torna problemático, pois, conhecer bem as dificuldades dos estudantes é essencial para traçar melhor os objetivos que se pretende chegar com o ensino. Assim, o desenvolvimento de estratégias de ensino da escrita mais eficazes necessita que o docente tenha ciência dos objetivos do seu ensino, que devem, inclusive, contemplar as dificuldades que os estudantes revelam ao acessarem a universidade.Segundo Anastasiou e Alves (2012) os professores, face aos problemas que se visibilizam nos processos de aprendizagem dosestudantes, sinalizam a necessidade de que os docentes produzam seus objetivos de ensino, com especial foco na clareza destes face às demandas que os estudantes apresentam.

Dito isso, a partir das narrativas dos colaboradores do estudo, foi possível compreender que os docentes têm variadas maneiras de lidar com a problemática da escrita acadêmica. Existindo 
docentes que desenvolvem estratégias de ensino mais superficiais e havendo outros que, ao contrário, demonstram possuir um repertório de estratégias de ensino da escrita mais amplo e completo:

E ai desde que eu cheguei, nós formamos um núcleo, [...], como o apoio de vários outros professores pra, um ciclo de formação, chamado Ciclo de Formação em Pesquisa. [...] Então, nós estamos fazendo tipo um curso de extensão para lidar com a escrita. [...] Uma estratégia também que a gente tem adotado é as monitorias das disciplinas. O Instagram "Bússola Acadêmica [...] éuma importante ferramenta para auxiliar os estudantes. [...] Em sala de aula, quando tem algum trabalbo que envolve uma produção cientifica eu geralmente faço um roteiro, né? E reservo uma aula para trabalhar aquilo(Flor, entrevista narrativa, 2020).

Então, quando são propostas atividades escritas é, nós orientamos os alunos a consultar os manuais, né? De trabalhos acadêmicos. [...] Há os manuais disponiveis na biblioteca da instituição. [...] Então, en normalmente, falo em linhas gerais do que se trata o gênero, do que eu espero deles. [...] recomendamos a consulta à ABNT, a consulta aos manuais de trabalhos acadêmicos (Sol, entrevista narrativa, 2020).

Diante das narrativas das duas docentes, é possível perceber que há diferenças claras na maneira como cada uma lida com a escrita acadêmica. A docente Flor ocupa-se em desenvolver um repertório de estratégias de ensino da escrita mais diversificado, auxiliando os estudantes, tanto dentro, como fora da sala de aula. Além de ocupar-se com os cursos de extensão para lidar com a escrita, a mesma empenha-se no incentivo às monitorias, nas quais, alunos com maior conhecimento da escrita, auxiliam os ingressantes. A docente ainda cita a criação da rede social, como ferramenta para atingir uma quantidade maior de estudantes, visto que, as redes sociais são um grande atrativo para os mesmos. Colaborativamente, essa professora ainda disponibiliza tempo e espaço no seu planejamento para tratar da escrita na sala de aula, demonstrando ter ciência da importância da mesma para o desenvolvimento pleno dos estudantes.

Tal postura demonstra a compreensão da docente de que as demandas de escrita na universidade variam até mesmo de uma disciplina para a outra. Assim, sua prática condiz com o que Castelló (2009, p.128) defendeao afirmar que: “[...] las formas de escritura de cada disciplina son particulares.”. Portanto, a preocupação com as especificidades do componente se articula com a abertura para superação de dificuldades que os estudantes enfrentam. Assim, ao criar um espaço em suas aulas para tratar do tema, Flor evidencia uma prática de acolhimento e de preocupação com os estudantes, gerando uma relação de proximidade que faz com que os discentes se sintam acolhidos em suas necessidades.

Entretanto, quando observamos as estratégias de ensino narradas pela docente Sol, percebemos que a mesma apresenta um repertório de estratégias de ensino da escrita mais vago, pois, apesar dela mencionar que realiza uma explanação em linhas gerais sobre algum tipo de texto que solicita aos alunos, isso não parece ser foco de suas aulas, nem ter espaço em seu planejamento. 
Ademais, quando os estudantes narram a respeito das estratégias de ensino da escrita postas em prática por seus docentes, identificamos a ausência de uma percepção clara sobre essas estratégias. Na maioria das narrativas fica evidente que os estudantes não conseguem enxergá-las. Tal compreensão, se visibiliza nos excertos a seguir, em que os estudantes evidenciam as (não) situações de ensino de escrita.

\footnotetext{
De todo o meu um ano e meio né que tô aqui apenas uma professora falou. Porque todos os outros querem parte escrita assim e assim. Introdução, desenvolvimento e conclusão, considerações finais né. Isso e aquilo. Ai fala que quer com formatação, com regras da ABNT, que você pode ver no site, não sei o que, aquilo. É uma coisa meio que jogada (Aline, entrevista narrativa, 2020).

Mas às vezes os docentes, eles solicitam um trabalho escrito. Eu vejo, eu percebi muito isso no início do meu, da minha graduação e eles não sinalizavam diretamente o que eles queriam. Por exemplo, ele pedia um artigo, ele não dava, um plano de como ele queria aquele artigo, de como ele queria aquela dissertação, que ele estava solicitando pra gente (Petrus, entrevista narrativa, 2020).
}

As narrativas evidenciam que os estudantes não percebem o emprego dessas estratégias de ensino por parte dos docentes. De maneira geral, o que aparece é a falta de orientações claras a respeito do que se espera da escrita dos estudantes. Ocorrendo uma prevalência de indicações de leituras, em detrimento de um ensino efetivo. Além disso, as narrativas nos evidenciam que isso ocorre desde os primeiros semestres dos cursos, período este, em que o ensino da escrita científica se faz ainda mais necessário, visto que, envolve o momento de ingresso dos estudantes na universidade, logo seus primeiros contatos com os gêneros textuais e exigências da escrita acadêmica.

Nessa seara reflexiva, a análise das narrativas referentes ao emprego de estratégias de ensino da escrita científica, por parte dos docentes, possibilitou-nos compreender que apesar da importância dessas estratégias de ensino, o emprego destas varia muito de docente para docente. Tendo em vista quea concepção de que os estudantes já deveriam ingressar na universidade com os saberes de escrita amplamente desenvolvidos, tal concepção impacta nas práticas de vários docentes, implicando na ausência de estratégias de ensino da escrita ou no desenvolvimento de estratégias vagas. Mas foi possível observar, também, que existem docentes que contrariamente, desenvolvem estratégias de ensino diversificadas.

\section{Estratégias de aprendizagem da escrita científica na universidade}

A aprendizagem da escrita requer dos estudantes equilíbrio e coordenação de inúmeros processos cognitivos e emocionais. Exige ainda que eles tenham conhecimento de si mesmos enquanto aprendizes, reconhecendo suas limitações e dificuldades. Ademais, a aprendizagem da escrita requer ainda que os estudantes lancem mão do uso de estratégias de aprendizagem eficazes. 
Quando se trata da escrita científica, as exigências costumam ser ainda maiores, isso por que, como o próprio Castelló (2009) afirma:

[...] escribir textos académicos es un proceso largo y complejo que requiere de una intensa actividad cognitiva que exige, como mínimo, buscar información, seleccionar la que consideremos más relevante, ordenar y organizar esta información em función de los proprios objetivos, y ensayar varias formulaciones sobre el papel hasta que, después de sucesivas revisiones, se consigue que el texto final se aproxime a lo que pretendíamos (CASTELLÓ, 2009, p. 123).

Portanto, compreendemos que a adoção dessas estratégias de aprendizagem configura-se como algo indispensável no processo de aquisição da aprendizagem deste tipo de escrita, que, como afirma o autor, é bastante complexa. Além disso, de acordo com Burochovitch e Santos (2011) estratégias de aprendizagem podem figurar em duas definições distintas.Uma delas é que as mesmas são sequências de procedimentos ou atividades que escolhemos com o objetivo de facilitar a aquisição, o armazenamento e a utilização de alguma informação. Assim sendo, as estratégias de aprendizagem podem ser engendradas pelo próprio sujeito aprendente e tornarem-se facilitadoras no processo de aprendizagem da escrita científica.

Posto isso, é importante frisar que Castelló (2009) nos aponta que para o desenvolvimento de uma competência estratégica da escrita científica é fundamental que os estudantes conheçam quais são as exigências cognitivas e afetivas inerentes à mesma. A demais, o autor afirma que:

El desarrollo de esta competencia estratégica implica ser capaz de tomar decisiones a lo
largo del proceso de composición acerca de la mejor forma de proceder en cada ocasión
em función del tipo de demanda, de los proprios objetivos de los recursos disponibles.
Decidir que en algunas ocasiones se requiere simplemente demonstrar lo aprendido o
que em otras es necesario un esfuerzo de planificación extra para conseguir los objetivos
del texto, requiere un nivel de conocimiento acerca de las proprias habilidades como
escritor, del tipo de demanda y de la situación comunicativa (profesor, objetivos,
asignatura), además de un proceso consciente de toma de decisiones, que permita ir
ajustando y regulando el proprio proceso de composición para acercarse a la consecución
de los objetivos(CASTELLÓ, 2009, p. 123).

Diante disso, entendemos que o desenvolvimento de tal competência não é algo simples que ocorre de forma espontânea, mas que faz parte de um longo processo, no qual, o docente possui um papel fundamental, no auxílio do discente, lhe possibilitando apropriar-se da linguagem acadêmica, de suas especificidades, para que o mesmo possa desenvolver estratégias de aprendizagem da escrita mais eficientes.

Com centralidade nos movimentos experienciais da vida acadêmica, em que os sentidos são revelados a partir do que o próprio estudante diz de si e de como constrói tais estratégias, as narrativas revelam modos próprios como cada sujeito, em sua realidade e condição, produz 
narrativamente sentidos para desvelar a construção de estratégias.Assim, diante das contribuições de tais sujeitos foi possível verificar que estes apresentam estratégias diversas como:

Eu sempre procuro na internet como deve ser feito. A partir daí, eu começo a ler. Gosto de ler antes de
escrever [...]. Então, eu leio primeiro sobre o conteúdo, estudo sobre o conteúdo, pra depois começar a por
em linhas [...]. Eu tive que pesquisar pra entender (Aline, entrevista narrativa, 2020).
Então, eu tenho que buscar fora da universidade e também de buscar através de leituras que en faço.
Através de qualquer coisa, dicas para minha escrita melhorar cada vez mais [...]. Eu reviso muito meus
textos quando eu vou produzi-los [...]. Eu procuro bastante, faço meu trabalho antes, peço ajuda de
professores que sei que são do ramo da metodologia, trabalham bastante com a ABNT (Petrus,
entrevista narrativa, 2020).

O movimento de compreensão de si, e do modo como cada sujeito tece a construção de suas estratégias, possibilita perceber que os estudantes possuem um repertório bastante interessante de estratégias de aprendizagem da escrita acadêmica. Tendo como estratégia comum o levantamento e leitura de fontes que lhes auxiliam a compreender melhor as normas técnicas e exigências dos gêneros textuais, e também dos conteúdos solicitados pelos docentes. Além desta, podemos destacar a revisão dos seus próprios textos e a busca pelo auxílio dos docentes. Assim, fica evidente que os estudantes estão sempre em busca de maneiras para enfrentarem suas dificuldades referentes à escrita. E tal movimento é feito a partir da condição que cada um imputa a si mesmo, na/pela condição que tem de buscar movimentos de aprendizagens na universidade.

Até mesmo as docentes entrevistadas conseguem visibilizar algumas estratégias de aprendizagem da escrita empregadas pelos discentes. Algumas dessas estratégias são precisamente a pesquisa e leitura de fontes, e a revisão dos textos, estratégias que, como se pode perceber, são também apontadas pelos estudantes. Nessa direção, docentes percebem a construção de estratégias por estudantes e evidenciam a construção de uma autonomia que se revela experiencialmente no movimento que o estudante faz para se autorregular. A respeito disso, a professora Sol reconhece que: "Mas, quando eles leem um pouco mais e revisam os textos que escrevem, consultando os manuais, como dicionários gramáticos, apresentam um texto um pouco melhor.” (Sol, entrevista narrativa, 2020).

Ademais, a docente Flor aponta outra estratégia que não é perceptível aos olhos dos estudantes, mas que, sem dúvida, é muito importante, pois, contribui não só para o enfrentamento das dificuldades de escrita dos mesmos, como também para a construção de uma relação professor estudante mais afetiva e dialógica. Tal estratégia é justamente a busca do diálogo com a docente quando estudantes possuem alguma dúvida em relação à escrita. Nesse sentido, Flor relata que: "E eles sugeriram, que en tivesse uma aula sobre normas de ABNT [...]" (Flor, entrevista narrativa, 2020). Assim, os estudantes buscaram vencer suas dificuldades com relação às normas técnicas, com a ajuda da docente. Tal atitude demonstra que os mesmos têm ciência da complexidade inerente à 
escrita acadêmica e que os desafios vivenciados por estes devem ser superados, também, com o apoio dos docentes.

No que tange ao ensino da escrita na universidade, sobretudo pela problemática evidenciada de dificuldades que os estudantes revelam ao acessarem o Ensino Superior, é imprescindível que os professores, em suas aulas, promovam o ensino das estratégias de aprendizagem da escrita. A propósito disso, Boruchovitch e Costa (2015) ainda definem como esse ensino deve ser posto em prática pelos docentes: "Deve-se ensinar poucas estratégias por vez, proporcionar inúmeras informações acompanhadas de vivências práticas bem orientadas relacionadas com tarefas de aprendizagem importantes e habituais de sala de aula." (BUROCHOVITCH e COSTA, 2015, p. 23).

Sendo assim, é possível compreender que a aquisição de estratégias de aprendizagem não ocorre de forma abrupta, mas sim, de forma tranquila e contínua. Segundo as autoras, a intervenção dos docentes por meio do ensino de estratégias de aprendizagem contribui significativamente para promover nos estudantes um aumento da capacidade de autorregularem sua própria aprendizagem. Isso não exclui a condição do estudante poder criar as suas próprias estratégias de aprendizagem da escrita na universidade. Muito pelo contrário, pois com o apoio e incentivo dos professores, o percurso que o estudante fará para se auto regular será ainda mais eficaz. A problemática central parece evidenciar que, mesmo reconhecendo a necessidade e eficácia da escrita acadêmica na universidade, ela pouco tem figurado como objeto de ensino dos planos dos professores. $\mathrm{O}$ caminho que muitos estudantes têm encontrado é mesmo um processo autorregulatório que evidencia modos próprios de ensinar a si mesmo os caminhos para a aprendizagem da escrita na universidade.

A autorregulação é algo imprescindível para a construção de aprendizagens significativas. Castelló (2009) também aponta a importância da autorregulação para a melhoria da escrita dos estudantes. Entretanto, ele afirma que é necessário: “[...] enseñar a los estudiantes a conocerprimero y a regular depués la propria escritura.” (CASTELLÓ, 2009, p. 131). Tal postura poderá contribuir de forma significativa para que os estudantes tenham sucesso em sua trajetória acadêmica, e, de igual modo, os professores.

\section{Considerações}

Tendo em vista os fatos apresentados a partir da análise dos dados da pesquisa que serviu de base para este trabalho, foi possível compreender que as principais estratégias de ensino da escrita científica, desenvolvidas pelas docentes participantes, relacionam-se às ações postas em 
prática dentro da sala de aula como a elaboração de roteiros para orientar os discentes em suas escritas, a indicação em aula de manuais acadêmicos. Como também, fora dela com a criação dos cursos de extensão, das redes sociais e monitorias para auxiliarem os estudantes em suas dificuldades com a escrita.

A partir da análise das narrativas dos discentes foi possível notar que tais estratégias de ensino não lhes são visíveis, sendo que os mesmos ainda se sente desamparados em suas dificuldades. Nesse cenário, suas narrativas demonstram que apenas um ínfimo número de professores investe no desenvolvimento de ensino que promova a produção de estratégias da escrita, enquanto foco, objeto e tema das aulas. As informações trazidas à baila narrativamente pelos participantes mostrou a necessidade de que as problemáticas da escrita acadêmica atravessem as salas de aulas, compondo repertório do ensino de do tema. Não basta reconhecer que os estudantes têm dificuldades, é central investir em ações de ensino que se ancorem na escrita acadêmica enquanto objeto do próprio ensino que se faz na universidade.

No que tange às estratégias de aprendizagem da escrita na universidade, foi possível verificar que os discentes põem em prática uma quantidade significativa de estratégias de aprendizagem da escrita, sendo que algumas delas advém de práticas de ensino desenvolvidas pelos docentes, ainda que isso não seja totalmente visível para os mesmos. Além disso, os discentes promovem o desenvolvimento de estratégias próprias como a revisão de seus próprios textos e a busca de professores para lhes auxiliar em suas dúvidas. Posto isso, é relevante relembrar que as atividades de escrita estão presentes de forma rotineira em praticamente todas as atividades desenvolvidas pelos estudantes no âmbito universitário.

Por fim, o estudo possibilitou compreender como o movimento narrativo se configura enquanto aspecto de constituição de vivências e experiências com a escrita na universidade. Ao narrar, o sujeito traz à tona suas lembranças, suas vivências, construindo modos próprios de significar e ressignificar o vivido. De igual modo, a escrita desse trabalho possibilitou que os pesquisadores empreendessem um movimento de compreensão e de interpretação, gerando condições de vivências e experiências com a escrita que se evidenciam nas tramas e tessituras do escrito que aqui se apresenta. Escrever não é fácil, mas é um caminho de constituição da existência reflexiva humana. Ao escrevermos esse texto, nos inscrevemos nele.

\section{Referências}

ANASTASIOU, L. G. C. ALVES, L. P.Processos de Ensinagem na Universidade: pressupostos para as estratégias de trabalho em aula. $5^{\text {a }}$ ed. Joinvile, SC: UNIVILLE, 2012. 
BORUCHOVITCH, E. SANTOS, O. J. X.Estratégias de Aprendizagem e Aprender a Aprender: Concepções e Conhecimentos de Professores.Psicol. cienc. prof., Brasília, v. 31, n. 2, p. 284295, 2011.

BORUCHOVITCH, E. COSTA, E. R. O Ensino de Estratégias de Aprendizagem no Contexto da Escrita.Psic. da Ed. São Paulo, no 41, p. 21-35. Dez. 2015.

CASTELLÓ, Montserrat. Aprender a escribir textos académicos: copistas, escribas, compiladores o escritores? In: POZO, Juan Ignácio. et. al. Psicoligía del aprendizaje universitário: la formación em competencias. Madrid. EDICIONES MORATA. 2009. Cap. 7.

JOVCHELOVITCH, Sandra; BAUER, Martin W. Entrevista narrativa. In: BAUER, Martin W. et al.Pesquisa qualitativa com texto, imagem e som: um manual prático. Petrópolis, RJ. VOZES. 2002. $2^{\mathrm{a}}$ ed.

MINAYO, Maria Cecília de Souza (org). Pesquisa social. Teoria, método e criatividade. 21. ed. Petrópolis: Vozes. 2008.

POZO, Juan Ignácio. Aprendizes e mestres: a nova cultura da aprendizagem. Porto Alegre. Artmed. 2002.

RICOEUR, P. Teoria da interpretação. Trad. de Artur Morão. Lisboa: Edições 70, 1996

SILVA, F. O da. Tessituras constitutivas da abordagem (auto) biográfica como dispositivo de pesquisa qualitativa. Práxis Educativa (Brasil) [en linea]. 2020, 15, 01-15. Acessado em 20 de Marzo de 2021]. ISSN: 1809-4031. Disponível em: https:/ /www.redalyc.org/articulo.oa?id=89462860001 